\title{
Maturation of endogenous glucose production in preterm and term calves ${ }^{1}$
}

\author{
J. Steinhoff-Wagner, ${ }^{*}$ S. Görs, ${ }^{*}$ P. Junghans, ${ }^{\star}$ R. M. Bruckmaier,† E. Kanitz, ${ }^{\star}$ C. C. Metges, ${ }^{*}$ \\ and H. M. Hammon*2 \\ *Leibniz Institute for Farm Animal Biology (FBN), 18196 Dummerstorf, Germany \\ †Veterinary Physiology, Vetsuisse Faculty, University of Bern, 3001 Bern, Switzerland
}

\section{ABSTRACT}

Glucose disposability is often impaired in neonatal calves and even more in preterm calves. The objective of this study was to investigate ontogenic maturation of endogenous glucose production (eGP) in calves and its effects on postnatal glucose homeostasis. Calves $(\mathrm{n}=7$ per group) were born preterm (PT; delivered by section $9 \mathrm{~d}$ before term) or at term ( $\mathrm{T}$; spontaneous vaginal delivery), or spontaneously born and fed colostrum for $4 \mathrm{~d}$ (TC). Blood samples were taken immediately after birth and before and $2 \mathrm{~h}$ after feeding at $24 \mathrm{~h}$ after birth (PT; T) or on d 4 of life (TC) to determine metabolic and endocrine changes. After birth (PT and T) or on d 3 of life (TC), fasted calves were gavaged with deuterium-labeled water to determine gluconeogenesis (GNG) and intravenously infused with $\left[\mathrm{U}^{13} \mathrm{C}\right]$-glucose to measure eGP and glucose oxidation (GOx) in blood plasma. After slaughter at $26 \mathrm{~h}$ after birth $(\mathrm{PT}, \mathrm{T})$ or on d 4 of life (TC), glycogen concentrations in liver and hepatic mRNA concentrations and enzyme activities of pyruvate carboxylase, phosphoenolpyruvate carboxykinase (PEPCK), and glucose-6-phosphatase were measured. Preterm calves had the lowest plasma concentrations of cortisol and 3,5,3'-triiodothyronine at birth. Plasma glucose concentrations from d 1 to 2 decreased more, but plasma concentrations of lactate and urea and glucagon:insulin ratio were higher in PT than in $\mathrm{T}$ and TC calves. The eGP, GNG, GOx, as well as hepatic glycogen concentrations and PEPCK activities, were lowest in PT calves. Results indicate impaired glucose homeostasis due to decreased eGP in PT calves and maturation of eGP with ontogenic development.

Key words: premature, gluconeogenesis, endogenous glucose production, gluconeogenic enzyme

\footnotetext{
Received March 10, 2011.

Accepted June 16, 2011.

${ }^{1}$ Part of the thesis of J. Steinhoff-Wagner accepted by the Faculty of Agricultural and Nutritional Science of the Christian-AlbrechtsUniversität zu Kiel, Germany.

${ }^{2}$ Corresponding author: hammon@fbn-dummerstorf.de
}

\section{INTRODUCTION}

Glucose is the main energy source during fetal development (Girard, 1990), but the continuous glucose supply by the placenta ceases with birth, and the neonate must meet glucose demands through endogenous glucose production (eGP) and lactose intake. Because eGP, especially gluconeogenesis (GNG), is negligible in the fetus, neonates have to adapt their glucose metabolism by maturation of the gluconeogenic pathway to ensure eGP. The maturation of this metabolic pathway is necessary because lactose intake is not sufficient to meet glucose demands in the neonate (Girard, 1990; Girard et al., 1992). Endocrine changes around birth, particularly the cortisol surge, regulate these maturation processes to establish eGP and GNG (Fowden et al., 1998). In addition, the cortisol surge causes elevated hepatic glycogen storage in the fetus that enables the neonate to provide glucose immediately after birth (Fowden et al., 1998).

In term-born neonates, enzyme activities involved in eGP and GNG change markedly during the first week of life and are affected by feeding (Ballard and Oliver, 1963; Grün, 1981; Hammon et al., 2003). Furthermore, the glucagon:insulin ratio in blood plasma is one of the most important regulators of GNG and eGP immediately after birth (Girard et al., 1992; Blum and Hammon, 1999). However, these endocrine changes also depend on food intake, as shown for neonatal pigs and calves (Lepine et al., 1989; Hammon and Blum, 1998; Rauprich et al., 2000). Interestingly, colostrum feeding stimulates GNG in hepatocytes of newborn piglets (Lepine et al., 1991). Therefore, postnatal maturation, endocrine changes, and feeding may act in concert to stimulate eGP and GNG in neonatal calves.

The maturation process of eGP close to term depends on ontogenic development and is probably impaired in preterm neonates because of insufficient endocrine action during late gestation. Preterm calves show severe hypoglycemia (Sangild et al., 2000; Bittrich et al., 2002) that may result from inadequate glycogen storage and deficiencies in eGP and GNG development (Bittrich et al., 2002; Schmidt et al., 2004). Although 
enzymes involved in eGP and GNG can be found in the fetal liver (Prior and Scott, 1977), glucose synthesis is obviously impaired in these calves. However, in vivo measurements of whole-body eGP and GNG in preterm born calves are rare.

The aim of this study was to characterize metabolic and endocrine changes, GNG, and eGP, as well as hepatic glucose metabolism in neonatal calves with different maturation degrees during the transition to extra-uterine life. Preterm calves were delivered 9 $\mathrm{d}$ before term by caesarean section to avoid the final cortisol surge at the end of gestation and to provide premature calves (Schmidt et al., 2004). These calves were compared with term-born and term-born calves fed colostrum for $4 \mathrm{~d}$, representing maturation at the end of gestation and during the initial postnatal colostral period, respectively. We tested the hypothesis that eGP and GNG depend on the degree of postnatal maturation and are associated with endocrine and hepatic changes related to endogenous glucose supply.

\section{MATERIALS AND METHODS}

\section{Animals and Feeding}

The experimental procedures were carried out according to the animal care guidelines and were approved by the relevant authorities of the State MecklenburgVorpommern, Germany (LALLF M-V/TSD/7221.31.1-014/07).

One female and 20 male German Holstein calves were studied. Calves ( $\mathrm{n}=7$ per group) were born preterm $(\mathbf{P T})$ or at term $(\mathbf{T})$ and were slaughtered $26 \mathrm{~h}$ after birth, or were born at term, fed colostrum for $4 \mathrm{~d}$, and slaughtered on d 4 of life (TC). Term-born calves ( $\mathrm{T}$ and TC) were spontaneously born at nearby commercial farms by vaginal delivery and were transported immediately after birth to the experimental facility. Preterm calves ( 1 female, 6 males) were delivered by caesarean section $9 \mathrm{~d}$ before expected parturition. All calves were born as singletons from multiparous cows. Calves were kept in single boxes at the Research Station of the University of Rostock (Dummerstorf, Germany) and housed at $19^{\circ} \mathrm{C}$ (room temperature) with straw bedding and free access to water.

Calves in the $\mathrm{PT}$ and $\mathrm{T}$ groups did not receive milk during the first day of life. Calves in group TC received previously collected, pooled colostrum obtained from milkings 1,3 , and 5 (d 1, 2, and 3 after parturition, respectively) on their first $3 \mathrm{~d}$ of life. Composition of the 3 colostrum milks was published previously (SteinhoffWagner et al., 2011). Fed amounts (per meal) of colostrum in group TC were $4 \%$ of BW on d 1 and $5 \%$ of BW from d 2 onward. Calves of group TC were fed by bottle twice daily (0800 and $1600 \mathrm{~h}$ ) unless otherwise indicated. All calves were fed colostrum at $5 \%$ of BW of colostrum (milking 5) $2 \mathrm{~h}$ before killing; that is, 26 $\mathrm{h}$ after birth for calves of group PT and $\mathrm{T}$ and on $\mathrm{d} 4$ for calves of group TC. The study design is illustrated in Figure 1. To ensure that all calves received an equal amount of colostrum, calves with reduced appetite were tube-fed their targeted portion.

Colostrum was collected before the study started. Cows housed at the farm where the calves were born were milked twice daily, and the colostrum of milkings 1,3 , and 5 after parturition was stored separately in plastic bottles at $-20^{\circ} \mathrm{C}$. Individual colostrum pools of milkings 1,3 , and 5 were prepared at the beginning of

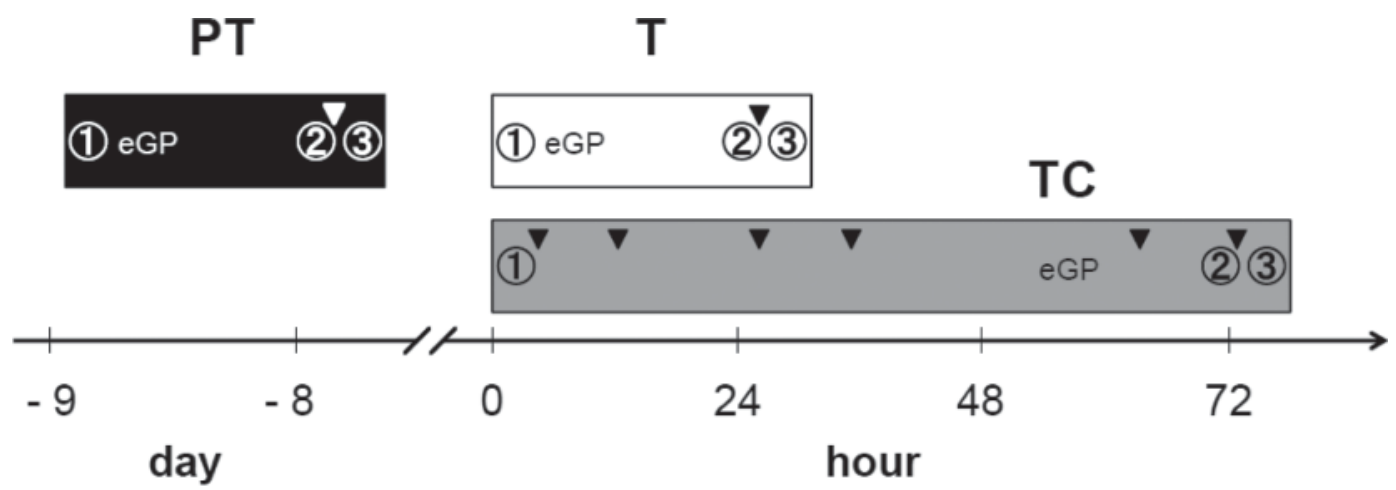

Time related to spontanous birth

Figure 1. Time line of the experimental study: Bars represent the period from birth to slaughter of preterm (PT, black), term (T, white), and term-born calves fed colostrum (TC, gray). Times of feedings are shown as triangles and time of blood sampling as numbered circles: 1 $=$ after birth; 2 = before food intake on d 2 (PT, T) or d 4 (TC); $3=2 \mathrm{~h}$ after food intake on d 2 (PT, T) or d 4 (TC). eGP $=$ endogenous glucose production. 
the study and then stored in plastic bottles at $-20^{\circ} \mathrm{C}$ until used to provide the same milk. Before feeding, colostrum was warmed in a water bath at $40^{\circ} \mathrm{C}$. All calves were injected subcutaneously with antibiotics $(25 \mathrm{mg}$ of enrofloxacin per $10 \mathrm{~kg}$ of BW; Baytril 5\%, Bayer AG, Leverkusen, Germany) on d 1 and calves of the TC group were additionally injected on d 2 and 3 . To avoid iron deficiency, calves received i.m. injections of iron dextran (10 mg/kg of BW; Ursoferran 100, Serumwerk Bernburg AG, Bernburg, Germany). Health status was evaluated daily based on the following clinical traits: rectal temperature, heart rate, respiratory rate, behavior, nasal discharge, respiratory sounds, fecal consistency, and navel inspection. Navels were disinfected with Betadine (Mundipharma Medical Company, Hamilton, Bermuda) after birth to protect calves from infection. Body weight was determined immediately after birth and before slaughter.

\section{Blood Sampling}

Two catheters (CertofixMono 340, Braun Melsungen AG, Melsungen, Germany) were inserted into the left and right jugular veins immediately after delivery in groups PT and T and on d 2 in group TC. Blood samples after birth were taken from the right jugular vein by vacuette (Greiner Bio-One International AG, Frickenhausen, Germany) in TC and by catheter in PT and T using S-Monovette (Sarstedt AG, Nürnberg, Germany). Additionally, blood samples were taken before $(24 \mathrm{~h}$ after birth in PT and T and $96 \mathrm{~h}$ after birth in TC) and $2 \mathrm{~h}$ after final feeding by catheter using S-Monovette (Figure 1). Tubes containing dipotassium EDTA $(1.8 \mathrm{mg} / \mathrm{mL}$ of blood) were used to measure plasma concentrations of glucose, lactate, NEFA, triacylglycerols (TAG), protein, albumin, urea, insulin, glucagon, IGF-1, 3,5,3'-triiodothyronine $\left(\mathbf{T}_{\mathbf{3}}\right)$, and thyroxine $\left(\mathbf{T}_{4}\right)$. Plasma cortisol concentrations were measured using tubes containing lithium heparin (14 to $15 \mathrm{IU} / \mathrm{mL}$ of blood). Blood was immediately put on ice and centrifuged at $1,500 \times g$ at $4^{\circ} \mathrm{C}$ for $20 \mathrm{~min}$; supernatant was stored at $-20^{\circ} \mathrm{C}$ until analyzed.

Endogenous glucose production and GNG were determined by combined intravenous $\left[\mathrm{U}_{-}{ }^{13} \mathrm{C}\right]$-glucose infusion and oral intake of deuterated water $\left({ }^{2} \mathrm{H}_{2} \mathrm{O}\right)$ in groups PT and T immediately after birth and in group TC on d 3 of life (Figure 1). All calves were without food before and during measurements. Calves were tube fed 2 boli of ${ }^{2} \mathrm{H}_{2} \mathrm{O}$ (per bolus: $10 \mathrm{~g} / \mathrm{kg}$ of BW, 70 atom $\%$ ${ }^{2} \mathrm{H}$, Chemotrade Ltd., Leipzig, Germany) within $4 \mathrm{~h}$ to estimate fractional GNG. The eGP was determined using a primed continuous intravenous infusion of $\left[\mathrm{U}_{-}{ }^{13} \mathrm{C}\right]-$ glucose [prime: $4.3 \mu \mathrm{mol} / \mathrm{kg}$ of BW; infusion: $6.4 \mu \mathrm{mol} /$ $(\mathrm{kg}$ of $\mathrm{BW} \times \mathrm{h})]$ dissolved in $0.9 \%$ saline and started immediately after the second ${ }^{2} \mathrm{H}_{2} \mathrm{O}$ bolus. Blood plasma samples were collected before and at 180, 240, 300, 360, $390,420,450$, and $480 \mathrm{~min}$ after the first ${ }^{2} \mathrm{H}_{2} \mathrm{O}$ bolus for tracer analysis in lithium-heparinized plasma. Whole blood was taken from lithium-heparinized monovettes and stored at $-20^{\circ} \mathrm{C}$.

Plasma concentrations of glucose, insulin, glucagon, and cortisol were determined in blood samples taken before and 180, 240,300,360,420,480, and $540 \mathrm{~min}$ after the first ${ }^{2} \mathrm{H}_{2} \mathrm{O}$ bolus. Blood plasma was prepared and stored as described above.

\section{Metabolite and Hormone Analyses}

Plasma metabolites (glucose, urea, NEFA, TAG, lactate, protein, and albumin) were analyzed by the Klinik für Rinder (Stiftung Tierärztliche Hochschule, Hannover, Germany) by using an automatic analyzer (Pentra 400, Axon Lab, Reichenbach, Germany) and the following kits: glucose (no. 553-230) and total protein (biuret reaction, no. 553-412) from MTL Diagnostics (Idstein, Germany); albumin (no. A11A01664), lactate (no. A11A01721), and TAG (no. A11A01640) from Horiba Europe GmbH (Hannover, Germany); NEFA (no. 434-91795) from Wako Chemicals GmbH (Neuss, Germany); and urea (no. LT-UR 0050) from Lehmann (Berlin, Germany). Plasma glucagon (kit from Linco Research, St. Charles, MO), insulin, IGF$1, \mathrm{~T}_{3}$, and $\mathrm{T}_{4}$ concentrations were measured by RIA as described previously (Hammon and Blum, 1997b, 1998). Glucagon:insulin and $\mathrm{T}_{3}: \mathrm{T}_{4}$ ratios were calculated on a molar basis. The determination of cortisol concentrations was derived from lithium-heparinized plasma. Plasma cortisol concentrations were analyzed in duplicate using a commercially available ${ }^{125}$ I-RIA kit (DSL Inc., Sinsheim, Germany) according to the manufacturer's guidelines. Cross-reactivities of antibody to prednisolone and corticosterone were 33.3 and 9.3\%, respectively, and to any further competing plasma steroids were $<4 \%$. The assay was validated for use with bovine plasma. The test sensitivity was $7.0 \mathrm{nmol} / \mathrm{L}$, and intra- and interassay CV were 5.6 and $6.3 \%$, respectively.

\section{Tracer Analyses in Blood}

Plasma $\left[\mathrm{U}_{-}{ }^{13} \mathrm{C}\right]$-glucose enrichment as well as positional deuterium $\left({ }^{2} \mathrm{H}\right)$ enrichment in plasma glucose were determined by GC-MS (QP2010, coupled with GC 2010, Shimadzu, Duisburg, Germany) as described recently (Junghans et al., 2010; Steinhoff-Wagner et al., 2011). Peak area ratios were converted to enrichments (molar percent excess; MPE) by using calibration curves based on known standard mixtures, as described previously (Junghans et al., 2010). 
To determine the ${ }^{13} \mathrm{C}$ abundance in blood $\mathrm{CO}_{2}$ derived from $\left[\mathrm{U}_{-}{ }^{13} \mathrm{C}\right]$-glucose oxidation, $\mathrm{CO}_{2}$ was liberated from $0.5 \mathrm{~mL}$ of heparinized whole blood and measured in the headspace by gas isotope ratio mass spectrometry (Delta Plus XL, Thermo Quest, Bremen, Germany) coupled with the Gas Bench II (Finnigan, Bremen, Germany), as described previously (Junghans et al., 2007; Steinhoff-Wagner et al., 2011).

Endogenous glucose production was calculated as rate of glucose appearance derived from intravenous $\left[\mathrm{U}_{-}{ }^{13} \mathrm{C}\right]$-glucose infusion as follows (van der Schoor et al., 2004; Steinhoff-Wagner et al., 2011):

$$
\mathrm{eGP}=\mathrm{I}_{\mathrm{IV}} \times\left[\left(\mathrm{IE}_{\mathrm{inf}} / \mathrm{IE}_{\mathrm{IV}}\right)-1\right],
$$

where $\mathrm{I}_{\mathrm{IV}}$ is the intravenous $\left[\mathrm{U}_{-}{ }^{13} \mathrm{C}\right]$-glucose tracer infusion rate $\left[\mu \mathrm{mol} \times(\mathrm{kg} \text { of } \mathrm{BW} \times \mathrm{h})^{-1}\right], \mathrm{IE}_{\text {inf }}$ is the isotopic enrichment (MPE) of $\left[\mathrm{U}^{13} \mathrm{C}\right]$-glucose in the administered infusate, and $\mathrm{IE}_{\mathrm{IV}}$ is the isotopic enrichment (MPE) of $\left[\mathrm{U}_{-}{ }^{13} \mathrm{C}\right]$-glucose tracer in plasma at isotopic steady state (360 to 480 min after infusion start). Absence of a statistically significant slope of plasma enrichment during the above time frame was confirmed by linear regression (Graph Pad Prism Software, Version 3.03, GraphPad Software, San Diego, CA).

The GNG method is derived from the ${ }^{2} \mathrm{H}$ incorporation at $\mathrm{C}-\mathrm{H}$ bonds of newly synthesized glucose (Junghans et al., 2010). The diagnostic positional ${ }^{2} \mathrm{H}$ enrichment in plasma glucose at position $\mathrm{C} 2[\mathrm{E}(\mathrm{C} 2)]$ originates from both GNG and glycogenolysis, whereas deuterium enrichment at position $\mathrm{C} 5[\mathrm{E}(\mathrm{C} 5)]$ is derived during GNG from phosphoenolpyruvate (PEP) and glycerol. The fractional GNG $\left(\mathrm{GNG}_{\text {fractional }}\right)$, representing the contribution of GNG to eGP, was calculated as the ratio of $\mathrm{E}(\mathrm{C} 5)$ to $\mathrm{E}(\mathrm{C} 2)$, as described previously (Junghans et al., 2010).

The absolute GNG rate $\left(\mathrm{GNG}_{\text {absolute }}\right)$ was calculated as

$$
\mathrm{GNG}_{\text {absolute }}=\left[\mathrm{GNG}_{\text {fractional }} / 100\right] \times \mathrm{eGP} .
$$

Fasted glucose oxidation [GOx; $\mu \mathrm{mol} \times(\mathrm{kg} \times \mathrm{h})^{-1}$ ] was computed according to the following equation (Steinhoff-Wagner et al., 2011):

$$
\begin{gathered}
\mathrm{GOx}={ }^{13} \mathrm{CO}_{2} \text { production } \cdot\left({ }^{13} \mathrm{C}\right. \text { plasma } \\
\text { glucose enrichment }){ }^{-1} \times 6,
\end{gathered}
$$

where ${ }^{13} \mathrm{C}$ plasma glucose enrichment (MPE) is the steady-state enrichment in the interval 360-480 min after start of the $\left[\mathrm{U}_{-}{ }^{13} \mathrm{C}\right]$-glucose infusion (steady state) multiplied by 6 , and

$$
\begin{gathered}
{ }^{13} \mathrm{CO}_{2} \text { production }= \\
\mathrm{V}\left(\mathrm{CO}_{2}\right) \times{ }^{13} \mathrm{CO}_{2} \text { blood enrichment } \times \mathrm{R}^{-1},
\end{gathered}
$$

where $\mathrm{V}\left(\mathrm{CO}_{2}\right)$ is the volume of carbon dioxide production $\left[\mu \mathrm{mol} \times(\mathrm{kg} \times \mathrm{h})^{-1}\right]$, and ${ }^{13} \mathrm{CO}_{2}$ blood enrichment is in atom percent excess. The $\mathrm{CO}_{2}$ production was measured by indirect calorimetry (Derno et al., 2009), in a subset of 5 additional newborn calves of the same age, and was $19.63 \mathrm{mmol} \times(\mathrm{kg} \times \mathrm{h})^{-1}(\mathrm{~J}$. SteinhoffWagner, I. Workel, M. Derno, and H. M. Hammon, Nutritional Physiology, Leibniz Institute for Farm Animal Biology, Dummerstorf, Germany, unpublished data). The result was comparable to that from other studies in calves (Metges et al., 1992). The recovery factor R $(81.4 \%)$ corrects for the incomplete recovery of tracer ${ }^{13} \mathrm{CO}_{2}$ in blood (Junghans et al., 2007).

\section{Analyses in Liver}

Calves were slaughtered $2 \mathrm{~h}$ after feeding at $26 \mathrm{~h}$ after birth (PT, T) or on d 4 of life (TC), the abdominal cavity was opened, and the liver was immediately removed. Tissue samples were snap-frozen in liquid nitrogen and stored at $-80^{\circ} \mathrm{C}$ until analyzed. All tissue samples were homogenized under liquid nitrogen. Dry matter was determined by freeze-drying (Duske et al., 2009). A kit from Roche Diagnostics (no. 207748; Roche Diagnostics, Mannheim, Germany) was used for measurement of glycogen concentrations in liver. According to the manufacturer's instructions, glycogen was converted to glucose by amyloglucosidase (EC 3.2.1.33) and glucose was analyzed by the hexokinase method (Hammon et al., 2009). Liver fat concentrations were calculated based on measured carbon and nitrogen content as described (Duske et al., 2009). Hepatic protein concentrations were determined by the method of Bradford (1976).

Total RNA was extracted using Trizol reagent (Invitrogen, Karlsruhe, Germany) and resuspended in diethyl pyrocarbonate-treated water. The integrity and purity of RNA were ensured by measurement of optical density $\left[\mathrm{OD}_{260} \times\left(\mathrm{OD}_{280}\right)^{-1}>1.9\right]$ and gel electrophoresis using ethidium bromide staining. The RNA was quantified by $\mathrm{OD}_{260}$ measurement. One microgram of total RNA was reverse transcribed into cDNA by application of random primers as described previously (Hammon et al., 2003) and purified using High Pure PCR Product Purification Kit (Roche Diagnostics). Abundance of mRNA was determined for pyruvate carboxylase (PC, EC 6.4.1.1), cytosolic (PEPCK-C) and mitochondrial (PEPCK-M) phosphoenolpyruvate carboxykinase (EC 4.1.1.32), and glucose-6-phosphatase (G6-Pase; EC 3.1.3.9) using a LightCycler (Roche Applied Sci- 
ence, Mannheim, Germany) and SYBR Green I for detection (Hammon et al., 2003). Specific primers were used to measure the mRNA concentrations of gluconeogenic enzymes and phosphoglycerate kinase 1 (PGK; EC 2.7.2.3); PGK was used as a reference gene because it was not affected by ontogenic development. Sequences of the gluconeogenic enzyme and PGK primers were published recently (Hammon et al., 2009; Steinhoff-Wagner et al., 2011). After detection, melting temperatures were checked for specificity of each product. Additionally, gel electrophoresis of the PCR product demonstrated only a single band of the expected size. Products were verified by sequencing using an ABI Sequencing kit (ABI Big Dye Terminator, Applied Biosystems, Darmstadt, Germany) and an ABI 310 Genetic Analyzer (Applied Biosystems). Values of crossing point (cp) for gluconeogenic enzymes and for PGK were corrected for different runs by an internal standard $(\Delta \mathrm{cp})$. In addition, $\Delta \mathrm{cp}_{\mathrm{PGK}}$ was used to normalize measurements of gluconeogenic enzymes as indicated by $\Delta \Delta \mathrm{cp}=\Delta \mathrm{p}_{\text {target }}-\Delta \mathrm{cp}_{\mathrm{PGK}}$ (Hammon et al., 2003). Efficiency of PCR was $>1.8$, and interand intraassay $\mathrm{CV}$ for reverse transcription-PCR of gluconeogenic enzymes and PGK genes were $<1 \%$.

Measurements of total (cytosolic and mitochondrial) PEPCK and PC activities in liver were described recently (Hammon et al., 2003; Steinhoff-Wagner et al., 2011). Liver tissue was homogenized in buffer (wt:vol = 1:3) containing $0.1 M$ sucrose, $50 \mathrm{~m} M$ potassium phosphate (pH 7.4), and 0.25 mM EDTA (pH 7.4). Samples were sonicated for $10 \mathrm{~s}$ to disrupt mitochondria. The homogenates were kept on ice at all times. Activities of PEPCK were determined in cell homogenates by measuring the carboxylation of phosphoenolpyruvate to oxaloacetate using $\mathrm{NaH}^{14} \mathrm{CO}_{3}$ (Ballard and Hanson, 1967b) with the addition of $\mathrm{NADH}$ and malate dehydrogenase to ensure the conversion of the reaction product, oxaloacetate, to malate (Atkin et al., 1979). Activities of $\mathrm{PC}$ were assayed in the crude homogenate by incorporation of $\mathrm{NaH}^{14} \mathrm{CO}_{3}$ into oxaloacetate and citrate in the presence of pyruvate (Atkin et al., 1979). Enzyme activities of G6Pase were measured according to Gierow and Jergil (1980). Liver samples were homogenized in $20 \mathrm{~m} M$ HEPES buffer containing 100 $\mathrm{m} M$ sucrose and $0.25 \mathrm{~m} M$ EDTA (wt/vol $=1: 10$ ). Glucose-6-phosphate was used as substrate. Produced phosphate concentrations were determined by the reaction with ammonium molybdate and compared with a phosphate standard curve (Mahuren et al., 2001).

\section{Statistical Analyses}

Results are presented as means \pm SE. Body weight, metabolites, and hormones were analyzed by the Mixed
Model of SAS (SAS/STAT 9.2, 2009; SAS Institute Inc., Cary, NC) with ontogenic group, time of blood sampling, and group $\times$ time interaction as fixed effects and individual calves as random effect. Data concerning gestation length of the cows, tracer enrichments, and measurements in liver were evaluated using the General Linear Model of SAS with group as main effect. Individual differences in both models were localized by Tukey $t$-test. The female calf was the consequence of unpredictable sex distribution in the PT group, but was never identified as an outlier when compared with PT male calves. Therefore, sex was not included into our model. The CORR procedure of SAS was used to calculate Pearson correlations between eGP rate, fractional GNG, plasma blood parameters, and enzyme activities as well as mRNA expression of gluconeogenic enzymes.

\section{RESULTS}

\section{Pregnancy Length, BW, and Food Intake}

Gestation length of cows was similar for $\mathrm{T}$ and $\mathrm{TC}$ cows $(283.7 \pm 2.7 \mathrm{~d}$ and $281.3 \pm 1.1 \mathrm{~d}$, respectively), but was about $9 \mathrm{~d}$ shorter $(P<0.01)$ for cows of group PT $(271.4 \pm 0.5 \mathrm{~d})$. Body weight at birth did not differ among term-born calves (T, TC), but tended to be lower $(P<0.1)$ in group $\mathrm{PT}$ than in groups $\mathrm{T}$ and $\mathrm{TC}$ $(41 \pm 0.7,46.3 \pm 2.5$, and $46.3 \pm 1.3 \mathrm{~kg}$ for PT, $\mathrm{T}$, and TC, respectively). Calves of group PT lost weight during the $24 \mathrm{~h}$ after birth. Body weight at tissue collection was lower $(P<0.05)$ in group PT than in groups $\mathrm{T}$ and $\mathrm{TC}(\mathrm{BW}$ was $37.3 \pm 0.8,45.2 \pm 2.2$, and $47 \pm 1.6 \mathrm{~kg}$ for $\mathrm{PT}, \mathrm{T}$, and $\mathrm{TC}$, respectively).

\section{Plasma Concentrations of Metabolites and Hormones at Birth and Before and After Food Intake After 24 h or $4 d$ of Age}

Plasma glucose concentrations were similar at birth, but on day of slaughter were higher $(P<0.05)$ before food intake in group TC than in group PT and tended to be higher $(P=0.1) 2 \mathrm{~h}$ after food intake in TC than in T (Table 1). Glucose concentrations increased $(P<0.05)$ after food intake in group PT. Plasma lactate concentrations were highest $(P<0.05)$ at birth in group PT, decreased after birth in group TC $(P<$ $0.05)$, and were highest $(P<0.05)$ at slaughter before and after feeding in group PT. Plasma NEFA concentrations were lowest $(P<0.05)$ at birth in group PT, increased $(P<0.05)$ during $24 \mathrm{~h}$ after birth in group PT, but decreased $(P<0.05)$ from birth to $\mathrm{d} 4$ in group TC, and decreased $(P<0.05)$ after feeding in all groups. Plasma TAG concentrations increased after 
birth $(P<0.05)$ in group TC and were highest $(P<$ $0.05)$ before and after feeding on $\mathrm{d} 4$ in group TC. Plasma protein concentrations increased $(P<0.05)$ from d 1 to d 4 , but decreased $(P<0.05)$ after feeding on $\mathrm{d} 4$ in group TC, and were highest $(P<0.05)$ on d 4 in group TC. Plasma albumin concentrations did not show any consistent group or time changes. Plasma urea concentrations were higher $(P<0.05)$ at birth in group PT than in group TC and were highest $(P<$ 0.05) before and after feeding in group PT.
Plasma insulin concentrations increased $(P<0.05)$ after feeding in all groups, and postprandial plasma concentrations were highest $(P<0.05)$ in group TC. Plasma glucagon concentrations were highest $(P<$ $0.05)$ at birth in group PT, but were higher on $\mathrm{d} 1$ before feeding in group PT than in group $\mathrm{T}$ and decreased $(P<0.05)$ after feeding in group PT. Glucagon to insulin ratios were highest $(P<0.05)$ at birth and before feeding in group PT and increased $(P<0.05)$ from birth to slaughter, but decreased $(P<0.05)$ after

Table 1. Plasma concentrations of metabolites and hormones immediately after birth and before and $2 \mathrm{~h}$ after feeding on $\mathrm{d} 2 \mathrm{of}$ life in preterm $(\mathrm{PT})$ and term $(\mathrm{T})$ born calves and on $\mathrm{d} 4$ of life in colostrum-fed (TC) calves ${ }^{1}$

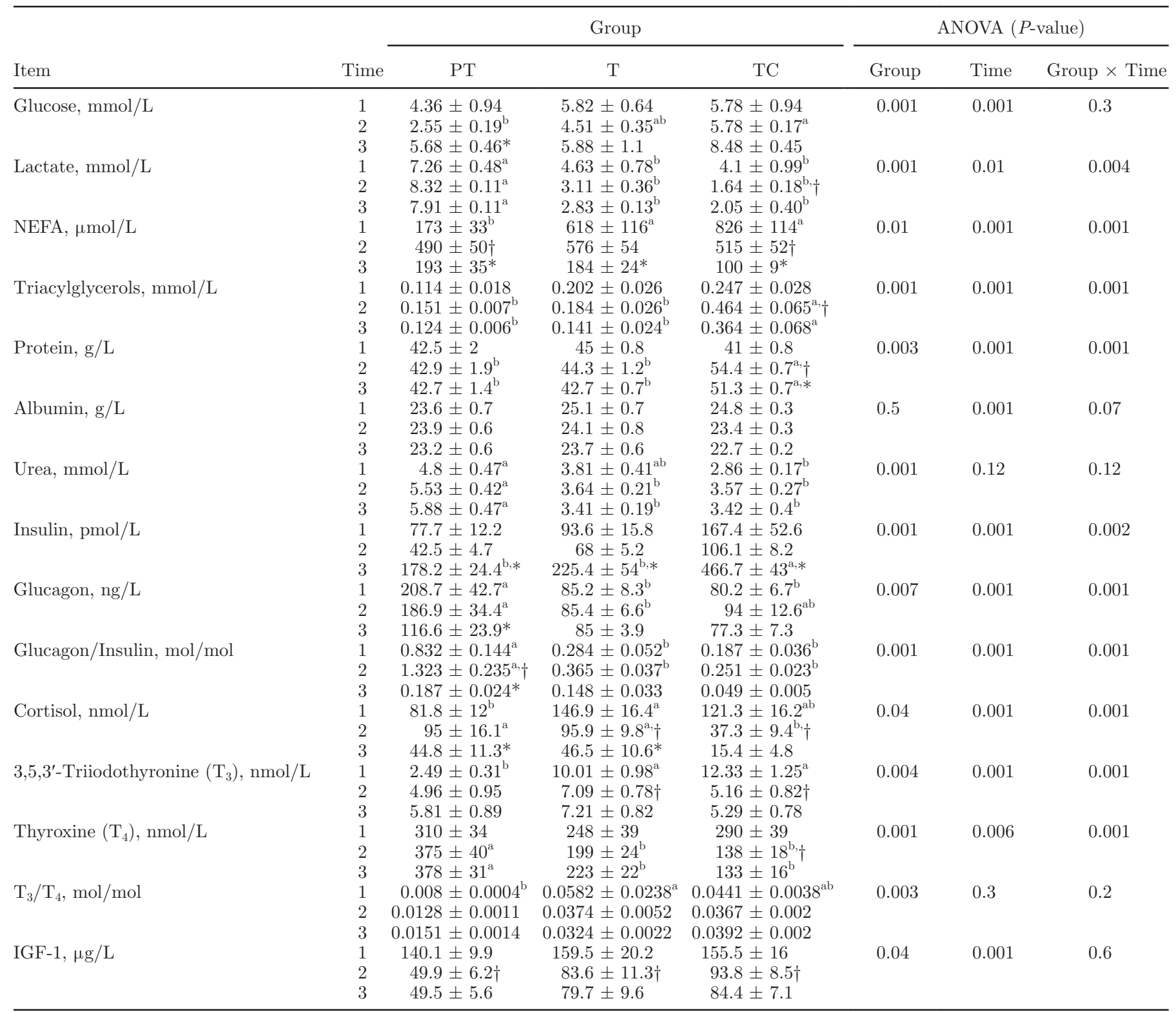

\footnotetext{
$\overline{\mathrm{a}, \mathrm{b}}$ Different letters within the same row indicate significant differences $(P \leq 0.05)$ between groups.

${ }^{1}$ Values are means $\pm \mathrm{SE}, \mathrm{n}=7$ per group. Time points: $1=$ after birth; $2=$ before food intake on $\mathrm{d} 2(\mathrm{PT}, \mathrm{T})$ or $\mathrm{d} 4$ (TC); $3=2 \mathrm{~h}$ after food intake on d 2 (PT, T) or d 4 (TC).

$\dagger$ Difference between time point 1 and 2 was significant $(P \leq 0.05)$; ${ }^{*}$ difference between time point 2 and 3 was significant $(P \leq 0.05)$.
} 
feeding in PT calves. Plasma cortisol concentrations were lower $(P<0.05)$ at birth in group PT than in group $\mathrm{T}$ and decreased $(P<0.05)$ from birth to $\mathrm{d} 1$ and 4 in groups $\mathrm{T}$ and TC. Cortisol concentrations were lowest $(P<0.05)$ before feeding in group TC and decreased after feeding in groups $\mathrm{PT}$ and $\mathrm{T}$. Plasma $\mathrm{T}_{3}$ and $\mathrm{T}_{4}$ concentrations decreased $(P<0.05)$ from $\mathrm{d} 1$ to $\mathrm{d} 4$ in group TC $(P<0.05)$ and $\mathrm{T}_{4}$ decreased after birth in $\mathrm{T}(P<0.05)$. Plasma $\mathrm{T}_{3}$ concentrations and the $\mathrm{T}_{3}: \mathrm{T}_{4}$ ratios were lowest $(P<0.05)$ at birth in $\mathrm{PT}$, but $\mathrm{T}_{4}$ concentrations at feeding were highest in group PT. Plasma IGF-1 concentrations decreased $(P<0.05)$ after birth in all groups. Plasma IGF-1 concentrations also indicated an ontogenic effect $(P<0.05)$ over all time points with lowest concentrations in PT.

\section{Plasma Concentrations of Metabolites and Hormones During Tracer Measurements}

Plasma glucose concentrations decreased $(P<0.05)$ during tracer infusion in all groups and were highest $(P<0.05)$ in group TC during the whole test period. Lowest values were observed at the end of the experiment in group PT (Figure 2A). Plasma insulin concentrations changed $(P<0.05)$ with time in all groups, and mean plasma insulin concentrations over time were highest $(P<0.05)$ in group TC (Figure 2B). Plasma glucagon concentrations changed over time $(P<0.05)$ in group $\mathrm{PT}$, concentrations before administration of the first ${ }^{2} \mathrm{H}_{2} \mathrm{O}$ bolus were higher $(P<0.05)$ in group PT than in group $\mathrm{T}$, and mean concentrations over time tended to be lowest $(P<0.1)$ in group $\mathrm{T}$ (Figure $2 \mathrm{C}$ ). Plasma cortisol concentrations decreased $(P<0.05)$ at the beginning of ${ }^{2} \mathrm{H}_{2} \mathrm{O}$ application and indicated a small increase $(P<0.05)$ at $4 \mathrm{~h}$ in all groups. Cortisol concentrations during the first $5 \mathrm{~h}$ of measurements, as well as mean cortisol concentrations over time, were highest $(P<0.05)$ in group T (Figure 2D).

\section{Measurements of eGP}

The eGP was lowest $(P<0.05)$ in group PT (Figure $3 \mathrm{~A})$. Fractional GNG was higher $(P<0.05)$ in group TC than in group PT and tended to be higher $(P=$ 0.1 ) than in group T. Fractional GNG tended to be higher $(P=0.1)$ in group $\mathrm{T}$ than in group $\mathrm{PT}$ (Figure 3B). Consequently, the absolute GNG was highest $(P<$ $0.05)$ in group TC and was higher $(P<0.05)$ in group $\mathrm{T}$ than in group PT (Figure 3C). Glucose oxidation was higher $(P<0.05)$ in group TC than in group PT and tended to be higher $(P=0.1)$ than in group T (Figure $3 \mathrm{D})$. Proportion of GOx relative to eGP was highest $(P$ $<0.05)$ in group PT (PT: $58.7 \pm 3.8 \%$, T: $30.4 \pm 3.8 \%$, TC: $33.4 \pm 1.6 \%)$.
Endogenous glucose production and fractional GNG were positively correlated $(\mathrm{r}=0.57 ; P<0.01)$ and were both positively correlated with basal glucose $(\mathrm{r}=0.51$; $P<0.05$ for eGP and $\mathrm{r}=0.66 ; P=0.001$ for fractional GNG). The eGP was negatively correlated with basal plasma glucagon concentrations $(\mathrm{r}=-0.45 ; P<0.05)$ and with glucagon:insulin ratio in plasma $(\mathrm{r}=-0.66$; $P<0.01)$.

\section{Measurements in Liver}

Hepatic protein concentrations were highest $(P<$ 0.05 ) in group $\mathrm{T}$ and fat concentrations were highest in group PT (Table 2). Glycogen concentrations in liver were highest $(P<0.05)$ in group TC. Hepatic abundance of PC mRNA was higher $(P<0.05)$ in group $\mathrm{T}$ than in group TC and tended to be higher $(P<$ 0.1 ) than in group PT. Abundance of G6Pase mRNA was higher $(P<0.05)$ in group PT than in group TC. Hepatic PEPCK activities were highest $(P<0.05)$ in group TC and were higher $(P<0.05)$ in group $\mathrm{T}$ than in group PT when calculated based on wet tissue. Hepatic G6Pase activities (per protein) were lower $(P<$ 0.05 ) in group $\mathrm{T}$ than in groups $\mathrm{PT}$ and TC (Table 2 ).

Expression of PC mRNA was positively correlated with the PC activities per gram of tissue $(\mathrm{r}=0.66 ; P$ $=0.001)$ and plasma cortisol concentration $(\mathrm{r}=0.44$; $P<0.05)$ and was negatively related to plasma glucose concentration $(\mathrm{r}=-0.43 ; P=0.05)$. Activities of PEPCK (per gram of tissue) were positively correlated with eGP $(\mathrm{r}=0.73 ; P<0.001)$, fractional GNG $(\mathrm{r}=$ $0.61 ; P<0.01)$, plasma glucose $(\mathrm{r}=0.56 ; P<0.01)$, and insulin $(\mathrm{r}=0.69 ; P<0.001)$ concentrations, but were negatively correlated with glucagon $(\mathrm{r}=-0.39 ; P$ $=0.08)$, glucagon:insulin $(\mathrm{r}=-0.66 ; P=0.001)$, and cortisol concentrations $(\mathrm{r}=-0.47 ; P<0.05)$. Plasma insulin concentrations and eGP were negatively correlated with G6Pase mRNA expression $(\mathrm{r}=-0.48 ; P<$ 0.05 for both correlations).

\section{DISCUSSION}

Because of their shortened gestation length, calves of PT had lesser BW compared with T and TC calves, which mirrors the high intensity of fetal growth during the last days of gestation in cattle (Thomsen, 1975). Body weight did not change in $\mathrm{T}$ and $\mathrm{TC}$ calves during the experimental period, whereas BW decreased in PT calves and differed from the BW change during first 24 $\mathrm{h}$ of life in $\mathrm{T}$ calves, which also did not receive milk. . Obviously, loss of body mass due to food restriction depends on maturation at birth and is accelerated in immaturely born calves. The PT calves were less mature due to the shorter gestation period, as indicated 
A

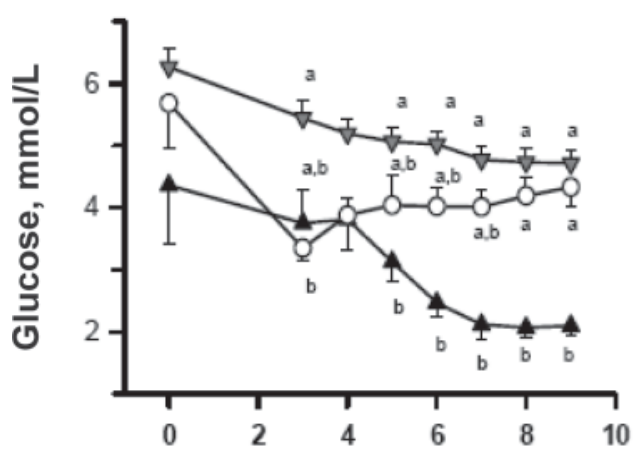

C

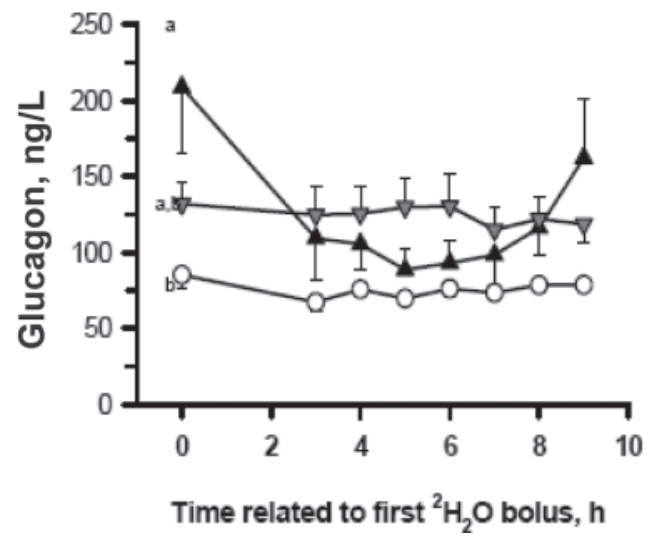

B

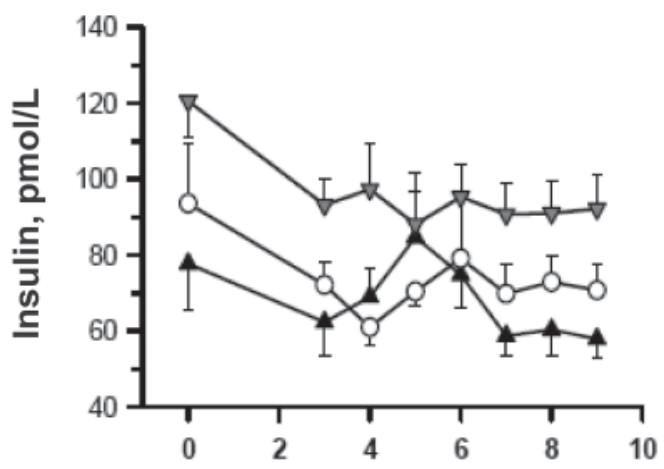

D

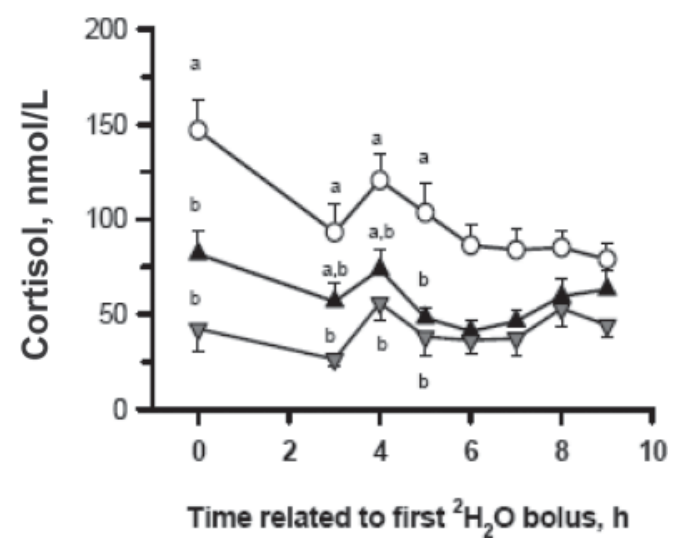

Figure 2. Plasma glucose (A), insulin (B), glucagon (C), and cortisol (D) concentrations during tracer test after birth in preterm (PT, $\mathbf{\Delta}$ ) and term $(\mathrm{T}, \mathrm{O})$ calves and on $\mathrm{d} 3$ of life in term calves fed colostrum (TC, gray triangles). Values are means $\pm \mathrm{SE}, \mathrm{n}=7$ per group. ${ }^{\mathrm{a}, \mathrm{b}}$ Different letters within the same time point show significant differences $(P \leq 0.05)$ among groups.

by decreased plasma cortisol concentrations after birth (Fowden et al., 1998), whereas T and TC calves showed comparable elevated cortisol levels around birth, as recently observed (Sangild et al., 2000).

\section{Ontogenic Effects on Postnatal Glucose Metabolism}

The importance of cortisol for maturation during neonatal development, especially glucose metabolism, is well documented (Fowden et al., 1998; Seckl, 2004; Drake et al., 2007). However, plasma glucose concentrations immediately after birth were not affected by extent of maturation, as reported previously (Bittrich et al., 2002), reflecting the importance of placental glucose supply to the fetus around birth (Silver et al., 1973; Ferrell et al., 1983). Plasma glucose concentrations during eGP measurement and $24 \mathrm{~h}$ after birth were considerably lower in PT calves than in $\mathrm{T}$ calves, and were lower than in TC calves on d 3 or d 4 of life. Therefore, unlike $\mathrm{T}$ calves, $\mathrm{PT}$ calves were not able to sustain plasma glucose homeostasis. Calves of the $\mathrm{T}$ group maintained plasma glucose homeostasis, al- though they were without food for $24 \mathrm{~h}$, which supports previous findings (Hadorn et al., 1997).

Plasma glucose increased after food intake in PT and TC calves, but not in T calves. Although postprandial glucose levels were comparable between PT and T calves and, therefore, PT calves were able to normalize their low preprandial plasma glucose concentrations by feeding, plasma glucose in TC calves increased to hyperglycemic levels after feeding. This finding confirms previous reports of elevated glucose absorption after colostrum feeding (Hammon and Blum, 1997a; Rauprich et al., 2000; Steinhoff-Wagner et al., 2011).

The distinct hypoglycemia before food intake in PT calves was primarily a result of lower eGP in PT calves than in T and TC calves. Obviously, eGP was not fully mature in PT calves, which could not sustain plasma glucose concentrations at the level of that in $\mathrm{T}$ and $\mathrm{TC}$ calves. Both glycogenolysis and GNG were reduced in PT calves. Our findings emphasize the importance of the last days before birth on the maturation of the gluconeogenic and glycogenolytic pathways. Calves born preterm were not able to meet glucose demands by 

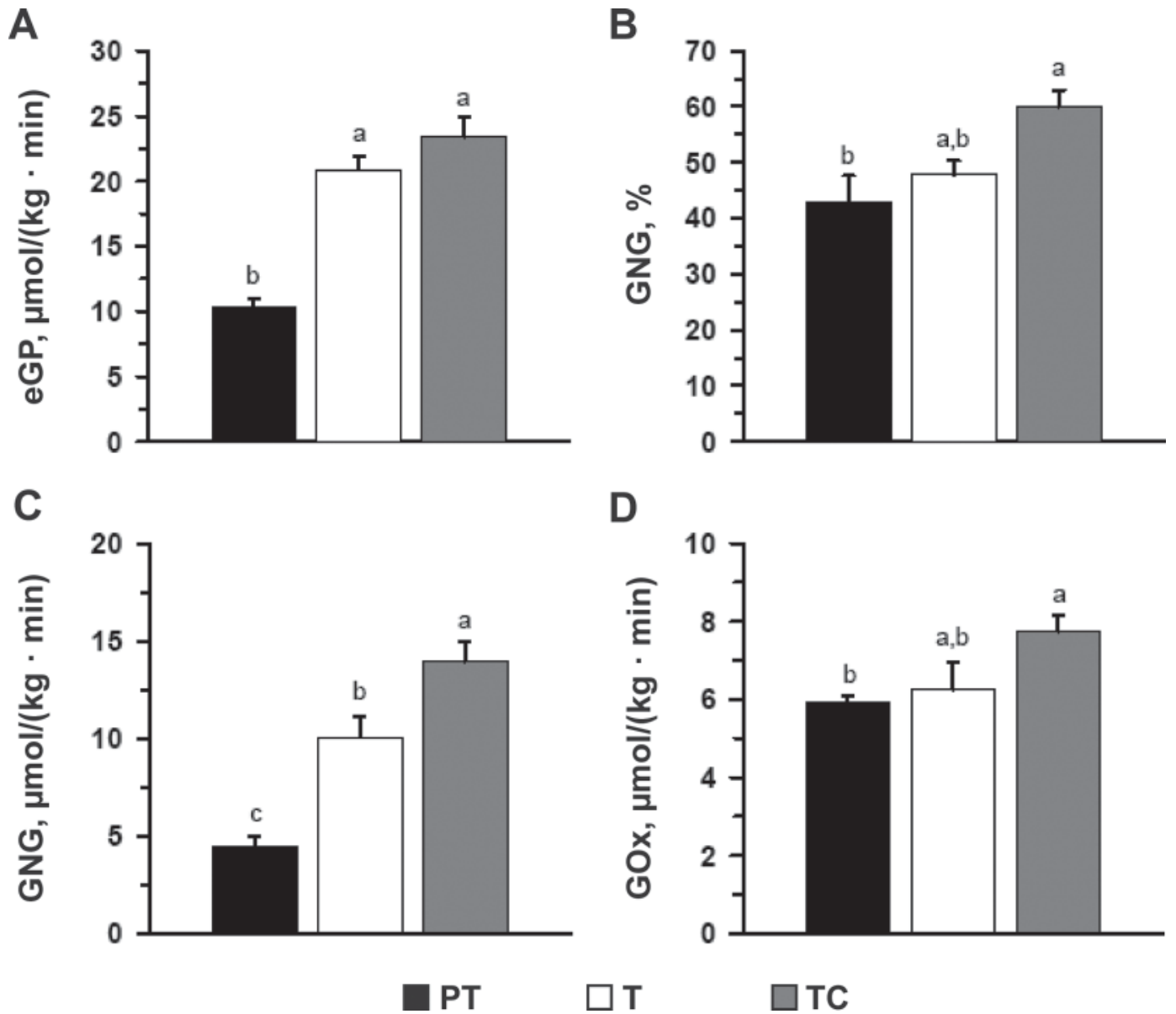

D

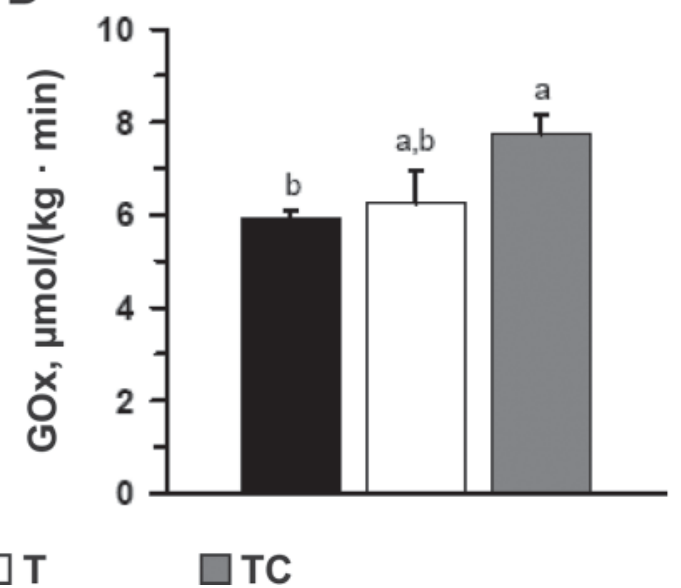

Figure 3. Endogenous glucose production (eGP, A), fractional gluconeogenesis (GNG, B), absolute GNG (C), and glucose oxidation (GOx, $\mathrm{D}$ ) after birth in preterm (PT, black bars) and term ( $\mathrm{T}$, white bars) calves and on d 3 of life in term calves fed colostrum (TC, gray bars). Values are means $\pm \mathrm{SE}, \mathrm{n}=7$ per group. ${ }^{\mathrm{a}-\mathrm{c}}$ Different letters show significant differences $(P \leq 0.05)$ among groups.

eGP, although hepatic GNG enzymes were expressed and active. Our data also indicated the importance of the cortisol surge around birth for maturation of enzymes involved in glucose production. The cortisol surge was impaired in PT calves (Schmidt et al., 2004), but it is not clear which steps of eGP were disturbed (Seckl, 2004). Interestingly, no differences of GNG were seen with regard to peripartum maturation in humans (Kalhan et al., 2001; van Kempen et al., 2003).

Concerning glucose metabolism in term-born calves, the differences in eGP between $\mathrm{T}$ and $\mathrm{TC}$ calves were small, yet TC calves exhibited higher GNG rates. A shift was observed from glycogenolysis to GNG as the main glucose-producing metabolic pathway with age, indicating that GNG becomes increasingly important for glucose supply during the neonatal period. Gluconeogenic activity was greater in TC calves, although these calves received lactose from milk during the first $2 \mathrm{~d}$ of life, whereas $\mathrm{T}$ calves received no lactose before eGP measurement. Therefore, food and especially lac- tose intake did not result in less GNG; rather, GNG was increased by food intake in 3-d-old calves, indicating the importance of GNG for glucose homeostasis in neonatal calves. A comparable level of eGP and GNG was observed when 3-d-old calves were fed a milk-based formula instead of colostrum (Steinhoff-Wagner et al., 2011). Therefore, elevated eGP and GNG in TC calves was not solely the consequence of colostrum intake with its high amounts of biologically active factors (proposed to stimulate GNG in neonates; Lepine et al., 1991; Blum, 2006), but rather was the consequence of nutrient intake per se or progressing age.

Glucose oxidation was greatest in TC calves, but the proportion of glucose oxidation relative to eGP was greatest in PT calves. The low glucose production rate but relatively high glucose oxidation in $\mathrm{PT}$ calves indicated decreased availability of other energy sources, such as fatty acids, to compensate for the reduced glucose status in PT calves. On the other hand, more glucose was available in TC calves for glycogen storage in 
Table 2. Protein, fat, and glycogen concentrations as well as gene expression and enzyme activities in liver $2 \mathrm{~h}$ after food intake in preterm (PT) and term (T) born calves on d 2 and in colostrum-fed (TC) calves on d 4 of life ${ }^{1}$

\begin{tabular}{|c|c|c|c|}
\hline \multirow[b]{2}{*}{ Item $^{2}$} & \multicolumn{3}{|c|}{ Group } \\
\hline & $\mathrm{PT}$ & $\mathrm{T}$ & $\mathrm{TC}$ \\
\hline Protein, mg/g & $121.3 \pm 0.43^{\mathrm{b}}$ & $139.9 \pm 0.22^{\mathrm{a}}$ & $116.6 \pm 0.37^{\mathrm{b}}$ \\
\hline Fat, $\mathrm{mg} / \mathrm{g}$ & $394.3 \pm 36.2^{\mathrm{a}}$ & $187.4 \pm 25.7^{\mathrm{b}}$ & $183.4 \pm 10.7^{\mathrm{b}}$ \\
\hline Glycogen, mg/g & $12.9 \pm 0.2^{\mathrm{b}}$ & $19.3 \pm 0.4^{\mathrm{b}}$ & $39.9 \pm 0.3^{\mathrm{a}}$ \\
\hline \multicolumn{4}{|l|}{ mRNA abundance } \\
\hline PC & $0.438 \pm 0.091^{\mathrm{ab}}$ & $1.030 \pm 0.322^{\mathrm{a}}$ & $0.183 \pm 0.039^{b}$ \\
\hline G6Pase & $6.02 \pm 1.81^{\mathrm{a}}$ & $4.30 \pm 0.82^{\mathrm{a}, \mathrm{b}}$ & $1.28 \pm 0.33^{\mathrm{b}}$ \\
\hline \multicolumn{4}{|l|}{ Enzyme activities per wet tissue } \\
\hline $\mathrm{PC}, \mathrm{nmol} /(\min \times \mathrm{mg})$ & $8.2 \pm 0.72$ & $10.5 \pm 1.69$ & $8.29 \pm 0.49$ \\
\hline PEPCK, $\mathrm{nmol} /(\min \times \mathrm{mg})$ & $1.32 \pm 0.18^{\mathrm{c}}$ & $2.65 \pm 0.32^{\mathrm{b}}$ & $4.1 \pm 0.4^{\mathrm{a}}$ \\
\hline G6Pase, $\mathrm{mmol} /(\min \times \mathrm{mg})$ & $0.371 \pm 0.012$ & $0.329 \pm 0.013$ & $0.371 \pm 0.013$ \\
\hline \multicolumn{4}{|l|}{ Enzyme activities per protein } \\
\hline $\mathrm{PC}, \mathrm{nmol} /(\min \times \mathrm{mg})$ & $67.8 \pm 5.7$ & $75.4 \pm 12.4$ & $67.8 \pm 5.7$ \\
\hline
\end{tabular}

${ }^{\mathrm{a}-\mathrm{c}}$ Different letters within the same row show significant differences $(P \leq 0.05)$.

${ }^{1}$ Values are means $\pm \mathrm{SE}, \mathrm{n}=7$ per group.

${ }^{2} \mathrm{PC}=$ pyruvate carboxylase; PEPCK-C = phosphoenolpyruvate carboxykinase-cytosolic; PEPCK-M = phosphoenolpyruvate carboxykinasemitochondrial; G6Pase = glucose-6-phosphatase.

the liver. Hepatic glycogen concentrations were highest in TC calves and, although measured in the postprandial state, the elevated glycogen concentrations in liver of TC calves were probably a result of not only lactose intake during 4-d feeding, but also of elevated GNG.

\section{Ontogenic Changes of Hormones and Additional Metabolites}

Although basal glucagon and the glucagon:insulin ratio in blood plasma were highest in $\mathrm{PT}$ calves and glucagon favors eGP as well as GNG (Donkin and Armentano, 1995), this was not sufficient in PT calves to stimulate eGP and GNG. Substrate availability was not the problem, because lactate and most of the free amino acids (J. Steinhoff-Wagner, S. Görs, C. C. Metges, and H. M. Hammon, Nutritional Physiology, Leibniz Institute for Farm Animal Biology, Dummerstorf, Germany, unpublished data) were higher in PT than in T calves. Probably, the low cortisol status in PT calves delayed maturation of endocrine regulation of eGP, which supports previous findings (Seckl, 2004; McCurdy and Friedman, 2006). On the other hand, hyperglycemia in TC calves on d 4 after feeding was combined with the highest postprandial plasma insulin concentrations. Elevated plasma insulin concentrations may reflect the improved glucose status in TC calves, which is also supported by highest hepatic glycogen concentrations in TC calves.

The decreased gluconeogenic activity in PT calves was consistent with the reduced thyroid status in PT calves. Plasma $T_{3}$ concentrations and the $T_{3}: T_{4}$ ratio, as well as plasma IGF-1 concentrations, were lowest in PT. The somatotropic axis is immature in neonatal calves and depends on glucocorticoid status in neonatal calves (Hammon and Blum, 1997b; Sauter et al., 2003); this may be even more the case for PT calves (Schmidt et al., 2004). In contrast, T and TC calves were subjected to high plasma concentrations of cortisol at birth and seemed to be able to convert $\mathrm{T}_{4}$ to $\mathrm{T}_{3}$. Thyroid hormones are important mediators of glucose homeostasis and, especially around birth, they are responsible for maturational effects; for example, glycogen storage (Boelen, 2009). Therefore, interactions between maturation effects of cortisol and thyroid hormones might be possible (Boelen, 2009), which supports our findings on improved glucose status in term-born calves.

Plasma lactate was highest in PT calves, as has been shown by others (Demigne and Rémésy, 1979). Plasma lactate is decreased more after delivery by section in term-born calves than in preterm calves (Sangild et al., 2000), which confirms our observations. Elevated plasma lactate concentrations may indicate less oxygen consumption or less lactate utilization; for example, as substrate for GNG or energy fuel, in PT calves, because lactate is an important substrate for GNG in neonates (Donkin et al., 1997). In addition, lactate serves as a substrate for the TCA cycle (Voet and Voet, 1994).

Plasma NEFA concentrations after birth were lowest in PT calves, but NEFA concentrations increased during the first day of life in PT calves. Obviously, a delay of fat mobilization occurred in PT calves. On the other 
hand, plasma NEFA concentrations decreased in TC calves with age, which primarily reflects feeding and improved energy supply in TC calves. In addition, PT and $\mathrm{T}$ calves did not indicate greater lipolytic activity than TC calves to compensate for impaired nutrient supply, although previous studies indicated elevated fat mobilization in fasted neonatal calves (Hadorn et al., 1997). One reason for the absence of differences of plasma NEFA concentrations might be the limited amount of fat depots in neonates, especially in preterm calves (Mellor and Cockburn, 1986). This was suggested by low subcutaneous and mesenteric fat in PT calves (J. Steinhoff-Wagner and H. Hammon; unpublished observations). Interestingly, preterm and term calves responded to nutrient supply in the same way by reducing plasma NEFA concentrations, indicating a comparable metabolic response after energy supply in $\mathrm{PT}$ and $\mathrm{T}$ calves. Improved lipid status in TC calves was indicated by higher plasma TAG concentrations that may have resulted from fat intake due to colostrum feeding in this group.

Plasma protein concentrations were highest in TC calves due to colostrum and especially immunoglobulin intake (Blum, 2006). On the other hand, PT calves showed the highest plasma urea concentrations throughout the study, which supports previous findings in preterm calves (Bittrich et al., 2002). Elevated plasma urea mainly indicates enhanced oxidation of amino acids, originating from the placenta, from muscle protein breakdown, or absorbed after protein digestion. Therefore, PT calves might have used amino acids to cover energy demands. We assume that amino acids were probably more important for energy supply than were fatty acids, especially in PT calves. In addition, the elevated glucagon:insulin status could favor protein degradation in PT calves.

\section{Ontogenic Effects on Hepatic Changes of Glucose and Fat Metabolism}

As noted, hepatic glycogen concentrations were highest in TC calves, which reflects the improved glucose status in these calves, and may result from both lactose intake and elevated GNG. Interestingly, oral glucose, and especially galactose, is preferentially used to synthesize hepatic glycogen when not used for energy utilization (Coombe and Smith, 1973). Hepatic fat concentrations were much higher in PT calves than in $\mathrm{T}$ and $\mathrm{TC}$ calves, the reasons for which are presently not known. However, elevated lipogenesis was seen in rat fetal liver compared with newborn liver (Ballard and Hanson, 1967a). We speculate that hepatic fatty acid metabolism was perhaps impaired in PT calves, resulting in less fatty acid oxidation and elevated fat storage in liver, as seen in piglets (Odle et al., 1991). The greater glucose oxidation relative to eGP in PT calves may support this assumption. Whether hepatic fatty acid oxidation in calves is immature at the end of pregnancy and therefore needs further maturation in PT calves is not known and requires further investigation (Ballard and Hanson, 1967a; Odle et al., 1991; Gustafsson, 2009).

Hepatic gene expression and activities of gluconeogenic enzymes could be measured in all ontogenic stages, which confirm previous studies in calves (Ontsouka et al., 2006). Hepatic activities of PEPCK are in agreement with in vivo GNG measurements; that is, they were lowest in PT calves that had the lowest GNG and were highest in TC calves that showed the greatest GNG. Interestingly, elevated plasma glucose and insulin concentrations did not attenuate PEPCK activities in TC calves, but probably reduced the mRNA abundance of G6Pase in TC calves (Jitrapakdee and Wallace, 1999; van Schaftingen and Gerin, 2002). On the other hand, enzyme activities of PC and G6Pase did not show a relationship to in vivo measurement of GNG. Therefore, gluconeogenic enzymes were differently affected by metabolic and endocrine changes and supported the findings in dairy cows (Hammon et al., 2009) that changes of gluconeogenic enzymes may be differently regulated. Furthermore, the abovementioned impairment of endocrine regulation on eGP in neonatal calves is probably reflected by the low endocrine response on gluconeogenic enzymes (Donkin et al., 1997; Scheuer et al., 2006). Changes in PEPCK activities indicate that this enzyme likely was a rate-limiting enzyme, but other gluconeogenic enzyme activities measured herein were more or less unaffected by changes in ontogenic state. Elevated gene expression of PC in T calves might point at differences in substrate utilization for GNG in $\mathrm{T}$ and $\mathrm{TC}$ calves; for example, the enhanced use of lactate for GNG in T calves. Lactate as substrate favors GNG through the PC pathway (Brockman, 2005). Differences in PC gene expression with respect to substrate utilization for GNG were also assumed in dairy cows, and gluconeogenic enzymes were variably regulated after calving in dairy cows (Hammon et al., 2009; Aschenbach et al., 2010).

\section{CONCLUSIONS}

Our study demonstrates impaired glucose metabolism and decreased in vivo eGP in PT calves. Obviously, GNG was not stimulated by endocrine changes in PT calves, although PT calves had an elevated plasma glucagon:insulin ratio and expressed hepatic gluconeogenic enzymes. Apart from oral glucose intake, the improved glucose status in TC calves is a result of 
enhanced eGP with an increasing proportion derived from GNG. Our study, therefore, stresses the importance of the final gestation period for maturation of glucose metabolism, especially on the maturation of eGP and GNG.

\section{ACKNOWLEDGMENTS}

We thank B. Waischnow, C. Reiko, S. Dwars, U. Lüdtke, I. Brüning, A. Fischer, P. Müntzel (FBN Dummerstorf), and Y. Zbinden (University of Bern) for analytical assistance, as well as A. Zeyner (University of Rostock) and her staff for providing the experimental facility. In addition, we thank O. Bellmann und A. Vernunft (FBN Dummerstorf) for performing the sections. Financial support by the Deutsche Forschungsgemeinschaft is gratefully acknowledged (Grant: HA 4372/5-1).

\section{REFERENCES}

Aschenbach, J. R., N. B. Kristensen, S. S. Donkin, H. M. Hammon and G. B. Penner. 2010. Gluconeogenesis in dairy cows: The secret of making sweet milk from sour dough. IUBMB Life 62:869-877.

Atkin, B. M., M. F. Utter, and M. B. Weinberg. 1979. Pyruvate carboxylase and phosphoenolpyruvate carboxykinase activity in leukocytes and fibroblasts from a patient with pyruvate carboxylase deficiency. Pediatr. Res. 13:38-43.

Ballard, F. J., and R. W. Hanson. 1967a. Changes in lipid synthesis in rat liver during development. Biochem. J. 102:952-958.

Ballard, F. J., and R. W. Hanson. 1967b. Phosphoenolpyruvate carboxykinase and pyruvate carboxylase in developing rat liver. Biochem. J. 104:866-871.

Ballard, F. J., and I. T. Oliver. 1963. Glycogen metabolism in embryonic chick and neonatal rat liver. Biochim. Biophys. Acta 71:578-588.

Bittrich, S., C. Morel, C. Philipona, Y. Zbinden, H. M. Hammon, and J. W. Blum. 2002. Physiological traits in preterm calves during their first week of life. J. Anim. Physiol. Anim. Nutr. (Berl.) $86: 185-198$.

Blum, J. W. 2006. Nutritional physiology of neonatal calves. J. Anim. Physiol. Anim. Nutr. (Berl.) 90:1-11.

Blum, J. W., and H. Hammon. 1999. Endocrine and metabolic aspects in milk-fed calves. Domest. Anim. Endocrinol. 17:219-230.

Boelen, A. 2009. Thyroid hormones and glucose metabolism: The story begins before birth. Exp. Physiol. 94:1050-1051.

Bradford, M. M. 1976. A rapid and sensitive method for the quantitation of microgram quantities of protein utilizing the principle of protein-dye binding. Anal. Biochem. 72:248-254.

Brockman, R. P. 2005. Glucose and short-chain fatty acid metabolism. Pages 291-310 in Quantitative Aspects of Ruminant Digestion and Metabolism. J. Dijkstra, J. M. Forbes, and J France, ed. CAB International, Wallingford, UK.

Coombe, N. B., and R. H. Smith. 1973. Absorption of glucose and galactose and digestion and absorption of lactose by preruminant calf. Br. J. Nutr. 30:331-344.

Demigne, C., and C. Rémésy. 1979. Fetal and postnatal metabolism in the calf. Ann. Biol. Anim. Biochim. Biophys. 19:159-165.

Derno, M., H. G. Elsner, E. A. Paetow, H. Scholze, and M. Schweigel. 2009. Technical note: A new facility for continuous respiration measurements in lactating cows. J. Dairy Sci. 92:2804-2808.

Donkin, S. S., and L. E. Armentano. 1995. Insulin and glucagon regulation of gluconeogenesis in preruminating and ruminating bovine. J. Anim. Sci. 73:546-551.
Donkin, S. S., S. J. Bertics, and L. E. Armentano. 1997. Chronic and transitional regulation of gluconeogenesis and glyconeogenesis by insulin and glucagon in neonatal calf hepatocytes. J. Anim. Sci. 75:3082-3087.

Drake, A. J., J. I. Tang, and M. J. Nyirenda. 2007. Mechanisms underlying the role of glucocorticoids in the early life programming of adult disease. Clin. Sci. 113:219-232.

Duske, K., H. M. Hammon, A. K. Langhof, O. Bellmann, B. Losand, K. Nürnberg, G. Nürnberg, H. Sauerwein, H. M. Seyfert, and C. C. Metges. 2009. Metabolism and lactation performance in dairy cows fed a diet containing rumen-protected fat during the last twelve weeks of gestation. J. Dairy Sci. 92:1670-1684.

Ferrell, C. L., S. P. Ford, R. L. Prior, and R. K. Christenson. 1983 Blood flow, steroid secretion and nutrient uptake of the gravid bovine uterus and fetus. J. Anim. Sci. 56:656-667.

Fowden, A. L., J. Li, and A. J. Forhead. 1998. Glucocorticoids and the preparation for life after birth: Are there long-term consequences of the life insurance? Proc. Nutr. Soc. 57:113-122.

Gierow, P., and B. Jergil. 1980. Spectrophotometric method for the determination of glucose-6-phosphatase activity. Anal. Biochem. 101:305-309.

Girard, J. 1990. Metabolic adaptations to change of nutrition at birth. Biol. Neonate 58:3-15.

Girard, J., P. Ferre, J. P. Pegorier, and P. H. Duee. 1992. Adaptations of glucose and fatty acid metabolism during perinatal period and suckling-weaning transition. Physiol. Rev. 72:507-562.

Grün, E. 1981. Ontogenetic development of enzymes of carbohydrate metabolism in liver of swine. Monatshefte für Veterinärmedizin 36:11-19.

Gustafsson, J. 2009. Neonatal energy substrate production. Indian J. Med. Res. 130:618-623.

Hadorn, U., H. Hammon, R. M. Bruckmaier, and J. W. Blum. 1997. Delaying colostrum intake by one day has important effects on metabolic traits and on gastrointestinal and metabolic hormones in neonatal calves. J. Nutr. 127:2011-2023.

Hammon, H., and J. W. Blum. 1997a. Prolonged colostrum feeding enhances xylose absorption in neonatal calves. J. Anim. Sci. 75:2915-2919.

Hammon, H., and J. W. Blum. 1997b. The somatotropic axis in neonatal calves can be modulated by nutrition, growth hormone, and Long-R-3-IGF-I. Am. J. Physiol. 36:E130-E138.

Hammon, H. M., and J. W. Blum. 1998. Metabolic and endocrine traits of neonatal calves are influenced by feeding colostrum for different durations or only milk replacer. J. Nutr. 128:624-632.

Hammon, H. M., S. N. Sauter, M. Reist, Y. Zbinden, C. Philipona, C. Morel, and J. W. Blum. 2003. Dexamethasone and colostrum feeding affect hepatic gluconeogenic enzymes differently in neonatal calves. J. Anim. Sci. 81:3095-3106.

Hammon, H. M., G. Stürmer, F. Schneider, A. Tuchscherer, H. Blum, T. Engelhard, A. Genzel, R. Staufenbiel, and W. Kanitz. 2009. Performance and metabolic and endocrine changes with emphasis on glucose metabolism in high-yielding dairy cows with high and low fat content in liver after calving. J. Dairy Sci. 92:1554-1566.

Jitrapakdee, S., and J. C. Wallace. 1999. Structure, function and regulation of pyruvate carboxylase. Biochem. J. 340:1-16.

Junghans, P., S. Görs, I. S. Lang, J. Steinhoff, H. M. Hammon, and C. C. Metges. 2010. A simplified mass isotopomer approach to estimate gluconeogenesis rate in vivo using deuterium oxide. Rapid Commun. Mass Spectrom. 24:1287-1295.

Junghans, P., J. Voigt, W. Jentsch, C. C. Metges, and M. Derno. 2007 The C-13 bicarbonate dilution technique to determine energy expenditure in young bulls validated by indirect calorimetry. Livest. Sci. 110:280-287.

Kalhan, S. C., P. Parimi, R. van Beek, C. Gilfillan, F. Saker, L. Gruca, and P. J. J. Sauer. 2001. Estimation of gluconeogenesis in newborn infants. Am. J. Physiol. Endocrinol. Metab. 281:E991-E997.

Lepine, A. J., R. D. Boyd, and J. Welch. 1989. Effect of colostrum intake on plasma glucose, non-esterified fatty acid and glucoregulatory hormone patterns in the neonatal pig. Domest. Anim. Endocrinol. 6:231-241. 
Lepine, A. J., R. D. Boyd, and D. M. Whitehead. 1991. Effect of colostrum intake on hepatic gluconeogenesis and fatty-acid oxidation in the neonatal pig. J. Anim. Sci. 69:1966-1974.

Mahuren, J. D., S. P. Coburn, A. Slominski, and J. Wortsman. 2001. Microassay of phosphate provides a general method for measuring the activity of phosphatases using physiological, nonchromogenic substrates such as lysophosphatidic acid. Anal. Biochem. 298:241-245.

McCurdy, C. E., and J. E. Friedman. 2006. Early foetal programming of hepatic gluconeogenesis: Glucocorticoids strike back. Diabetologia 49:1138-1141.

Mellor, D. J., and F. Cockburn. 1986. A comparison of energy metabolism in the new-born infant, piglet and lamb. Q. J. Exp. Physiol. 71:361-379.

Metges, C. C., H. L. Schmidt, and H. Eichinger. 1992. Use of naturally enriched mixed food in $13 \mathrm{C}$ breath tests applied in young suckling calves. Br. J. Nutr. 67:43-55.

Odle, J., N. J. Benevenga, and T. D. Crenshaw. 1991. Postnatal age and the metabolism of medium- and long-chain fatty acids by isolated hepatocytes from small-for-gestational-age and appropriatefor-gestational-age piglets. J. Nutr. 121:615-621.

Ontsouka, E. C., Y. Zbinden, H. M. Hammon, and J. W. Blum. 2006. Ontogenesis of mRNA levels and binding sites of hepatic alpha-adrenoceptors in young cattle. Domest. Anim. Endocrinol. 30:170-184.

Prior, R. L., and R. A. Scott. 1977. Ontogeny of gluconeogenesis in the bovine fetus: Influence of maternal dietary energy. Dev. Biol. 58:384-393.

Rauprich, A. B. E., H. M. Hammon, and J. W. Blum. 2000. Effects of feeding colostrum and a formula with nutrient contents as colostrum on metabolic and endocrine traits in neonatal calves. Biol. Neonate 78:53-64.

Sangild, P. T., M. Schmidt, H. Jacobsen, A. L. Fowden, A. Forhead, B. Avery, and T. Greve. 2000. Blood chemistry, nutrient metabolism, and organ weights in fetal and newborn calves derived from in vitro-produced bovine embryos. Biol. Reprod. 62:1495-1504.

Sauter, S. N., E. Ontsouka, B. Roffler, Y. Zbinden, C. Philipona, M. Pfaffl, B. H. Breier, J. W. Blum, and H. M. Hammon. 2003. Effects of dexamethasone and colostrum intake on the somatotrop- ic axis in neonatal calves. Am. J. Physiol. Endocrinol. Metab. 285:E252-E261.

Scheuer, B. H., Y. Zbinden, P. Schneiter, L. Tappy, J. W. Blum, and H. M. Hammon. 2006. Effects of colostrum feeding and glucocorticoid administration on insulin-dependent glucose metabolism in neonatal calves. Domest. Anim. Endocrinol. 31:227-245.

Schmidt, M., P. T. Sangild, J. W. Blum, J. B. Andersen, and T. Greve. 2004. Combined ACTH and glucocorticoid treatment improves survival and organ maturation in premature newborn calves. Theriogenology 61:1729-1744.

Seckl, J. R. 2004. Prenatal glucocorticoids and long-term programming. Eur. J. Endocrinol. 151(Suppl. 3):U49-U62.

Silver, M., D. H. Steven, and R. S. Comline. 1973. Placental exchange and morphology in ruminants and the mare. Pages 245-271 in The Sir Joseph Barcroft Centenary Symposium: Foetal and Neonatal Physiology. K. W. Cross, ed. Cambridge University Press, New York, NY.

Steinhoff-Wagner, J., S. Görs, P. Junghans, R. M. Bruckmaier, E. Kanitz, C. C. Metges, and H. M. Hammon. 2011. Intestinal glucose absorption but not endogenous glucose production differs between colostrum- and formula-fed neonatal calves. J. Nutr. 141:48-55.

Thomsen, J. L. 1975. Body length, head circumference, and weight of bovine fetuses: Prediction of gestational age. J. Dairy Sci. 58:1370-1373.

van der Schoor, S. R. D., B. Stoll, D. L. Wattimena, H. A. Buller, D. Tibboel, D. G. Burrin, and J. B. van Goudoever. 2004. Splanchnic bed metabolism of glucose in preterm neonates. Am. J. Clin. Nutr. 79:831-837.

Van Kempen, A. A. M. W.. J. A. Romijn, A. F. C. Ruiter, M. T. Ackermans, E. Endert, J. H. Hoekstra, J. H. Kok, and H. P. Sauerwein. 2003. Adaptation of glucose production and gluconeogenesis to diminishing glucose infusion in preterm infants at varying gestational ages. Pediatr. Res. 53:628-634.

van Schaftingen, E., and I. Gerin. 2002. The glucose-6-phosphatase system. Biochem. J. 362:513-532.

Voet, D., and J. G. Voet. 1994. Chapter 21: Other pathways of carbohydrate metabolism. Pages 599-625 in Biochemistry. John Wiley and Sons, New York, NY. 